\title{
Mitigating cybersecurity insider threat in the hiring stage of the employee lifecycle
}

\author{
Catherine Ayodele \\ Computing department \\ Bournemouth University \\ Bournemouth, United kingdom \\ S5318903@bournemouth.ac.uk
}

Abstract - Cybersecurity insider threat is costly to organisations and due to the amount of privilege the attacker possesses, detection is typically difficult. This has created a need for early prevention by reducing risks through a comprehensive recruitment process. This paper explores human-focused mitigation techniques by evaluating findings from researchers in cybersecurity personnel management. It analysed the effect of human resource practices such as hiring policies, employment practices and employee screening in protecting organisations from insider threats which would subsequently reduce risks and overall costs in organisations.

Keywords-Insider threat, Information security, Human resources, Mitigation, Vulnerabilities, Recruitment

\section{INTRODUCTION}

Cybersecurity problems are human problems [1]. This is because human vulnerabilities remain one of the most persistent challenges to an organisations information security programme. Common threats such as social engineering attacks, ransomware, human error and other insider threats indicate that humans remain the weakest element for compromise of the confidentiality, integrity and availability of data.

According to ENISA [2], an insider threat is an event whose threat actor is related to or working with the victim of the cyber incidence. This can sometimes be defined as an event caused by legitimate users who misuse their access to the network of an organization [3]. The costs associated with insider threats have been on the increase over the years and these include financial, economic and reputational damage to organisations. It is estimated that organisations spend an average of $\$ 11.45 \mathrm{M}$ [4] to recover from insider threat attacks.

Information security management involves the management of people, processes and technology [5]. Technological controls involve the technology used to identify threats and vulnerabilities, secure data and detect abnormal behaviours. This is usually put in place with the right processes which involve procedures, policies and guidelines for implementing controls. This technology and process however sophisticated are expected to be implemented by people.

There has been numerous research conducted on technological solutions to mitigate security risks [6-8], but there have been few studies focusing on information security governance [9] and more specifically human resources. According to Warkentin and Willington [10], this is because most researchers are focused on external threats rather than internal threats caused by employees. To effectively mitigate the insider threat, there is a need for organisations to practice effective human resource management practices from the start of employees journey into the organisation until their exit to minimise risks posed by insider threats. Măzăreanu [11] described people as the primary source of risks in an organisation, hence effective people management should focus on implementing the right approach to mitigate risk associated with humans in the organization[12-14].

This study aims to critically assess information security personnel management practices through the first stage of an employee lifecycle in organisations and to provide recommendations to organisations for reducing human vulnerabilities that increase the risks of insider threats.

Due to the constraints of time and cost, secondary data alone will be sufficient for the paper. This would be a literature review of previously published researches such as publications from Conrad [15], Silowash et al. [16], and ENISA [2].

\section{RELATED WORKS}

Previous researchers have focused on insider threat and administrative mitigation of identifying insider threat through behavioural monitoring approach [17-22]. Andersen et al. [8] recommended a system dynamics model for detecting insider threats stating that early risk management can reduce the impact of an insider threat attack. The authors also mentioned that there are various limitations to technical approaches. Greitzer [20] researched the relationship between employee behaviour and insider threat concluding that certain behaviours make employees more likely to cause sabotage but he did not address the role of human resources in the early identification of employee behaviour. Warketin and Willington [10] agreed that mitigating insider threats requires a combination of sociotechnical approaches and supported future investigations of these approaches. However, only a few authors [15] have investigated the role of human resources using the employee lifecycle model. While Conrad [15] focuses on the motive, opportunity and means throughout the hiring stage using case studies, this paper focuses on best practices for managing the recruitment stage of the employee lifecycle.

\section{RECRUITMENT STAGE}

The recruitment stage is the first phase in an insider threat actor journey with the targeted organisation. For most organisations, planning and hiring occur during this stage and the following tasks should be security focused [22].

\section{Policy and process definition}

2. Assessment and Pre-employment verification . 


\section{A. Policy and Processes definition}

Hiring policies and processes designed must adhere to recognised standards and guidelines such as CREST, NIST and ENISA [2]. These should be targeted to provide a preventive and proactive approach to addressing security risks which is effective in the management of insider threats. Hunker et al [23] argue that applying only a proactive approach may not necessarily be the best strategy for mitigating insider threat, they suggest that a combination of proactive and reactive approaches would be better. ENISA [2] however recommends that for effective management of insider threats, recruitment policies should first address recruitment challenges that increase an organisations risks, these challenges include:

\section{i. Conflicts of interests}

ii. Corruption

iii.Falsification of documents/information

iv. Favouritism

v. Lack of control/crosschecking of documents received

vi. Leakage of information

vii. Non-compliance

viii. Intentional destruction of records [2]

To compensate for the skill gaps present in some roles, some organisations outsource employees [1]. This however comes with various risks and [24] argues that outsourcing increases the risk of insider threats. Colwill [7] also mentioned that outsourcing easily converts external threats to internal threats making detection more difficult.

Aside from hiring policies, other human resource policies governing people management affects the likelihood of insider threats. CERT recommends the inclusion of policies such as Job rotation, Separation of duties and leave management. These have been found to reduce cyber fraud and reduce stress at work[25].Proper onboarding and regular Training can reduce human error and unintentional insider threats. Table 1 shows recommended Human resource practices and threats that can be prevented when implemented

These practices are useful in mitigating insider threats because employees get motivated to commit cybersecurity crimes for money, revenge, or intellectual challenge [1]. [26] also added that employees are triggered by the work environment, personal factors, and opportunity. Table 1 shows best practices to be implemented in human resource information security policies that reduce Insider attacks.

Policies are only useful when they are communicated updated and understood. These policies must be communicated to employees during the hiring stage, signed to show acknowledgement [27] and regular training on changes should be conducted by the human resource department.

\section{B. Employment screening}

Employment screening should be done based on job role requirements, background checks and behavioural screenings.
First, organisations should determine a baseline skill competency along with the job description and selected candidates must meet these requirements. This helps to mitigate unintentional insider threats due to a lack of skills Dhillon and Moores(2001). These must be planned in consideration of the organisation's strategy. Allocating too many tasks to one role may increase the likelihood of undetected fraud. Identification of the organisation skill gap and taking a skill inventory will help reduce risks in the organisation. Matching overqualified employees to lower roles or overburdening employees with more tasks can lead to frustration which can eventually lead to malicious acts.

CERT [16] recommends that assessments should include interview/behavioural assessments/health checks/ psychological assessments and background checks. According to research conducted by CERT, 30\% of malicious insider threats were conducted by employees who had a criminal record [16]. The checks should be communicated to candidates to avoid legal issues [2].

Baseline verification criteria should include

- Identity confirmation

- Character references

- Curriculum vitae checks

- Credit checks

- Criminal record checks

- Regulatory screening requirements such as BPSS and security clearance [16].

Vetting of employees is a very important requirement in high-risk industries such as health, this must happen before the recruit is allowed to begin the new role. Emma [25] and Cappelli et al [28] recommended that employees can begin work before completing the vetting but under probatory status. For high-security level jobs, a security clearance must be obtained, this is a more in-depth screening test. Conrad [15] however argued that obtaining clearance does not exempt insider threat actors from infiltrating the organisation. This could be due to a change in employees behaviour later down the employment cycle [8]. The NIAC, however, mentioned that a major obstacle to employment screening is due to lack of even employment practices arising from various standards of screening around the world such as limited access, the scope of investigation data and unacceptability of screening practices, these are obstacles to effective insider threat mitigation programs.

Reference checks from past employers can reveal highrisk behaviours such as absenteeism, poor performance, relationship problems with colleagues and a history of inappropriate behaviours [29]. Financial checks can also give indications about money grievances and potential embezzlements which may increase the risk of financial crimes. Zajac [1] states that employees get motivated to commit cybersecurity crimes for money, revenge, or intellectual challenge. Dhillon and Moores [26] also added that employees are triggered by the work environment, personal factors, and opportunity. 


\section{Figures and Tables}

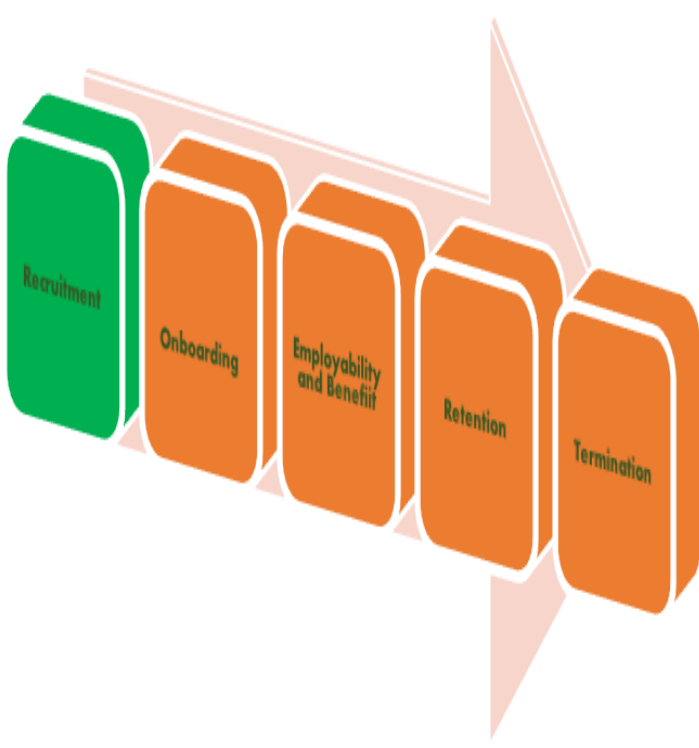

a)

Fig 1. Illustration of the employee life cycle in the organisation[30-32]

Table 1. Recommended practices to be implemented in Human resource information security policies that reduce Insider attacks [25].

\begin{tabular}{|c|c|}
\hline $\begin{array}{c}\text { Human resources } \\
\text { practice }\end{array}$ & Threats Mitigated \\
\hline Job rotation & $\begin{array}{c}\text { Fraud, Lack of expertise, } \\
\text { boredom }\end{array}$ \\
\hline Leave management & Employee Burn out, fraud \\
\hline $\begin{array}{c}\text { Career development } \\
\text { and training }\end{array}$ & $\begin{array}{c}\text { Lack of expertise, } \\
\text { Dissatisfaction, Lack of } \\
\text { motivation, Sabotage }\end{array}$ \\
\hline $\begin{array}{c}\text { Medical services and } \\
\text { health service in the Work } \\
\text { environment } \\
\text { Budget for sufficient } \\
\text { staffing }\end{array}$ & $\begin{array}{c}\text { Grievances, } \\
\text { Dissatisfaction }\end{array}$ \\
\hline Segregation of duties & Access misuse, fraud \\
\hline Training and awareness & $\begin{array}{c}\text { Phishing attacks, social } \\
\text { engineering }\end{array}$ \\
\hline
\end{tabular}

\section{CONCLUSION}

This paper aimed at critically assessing information security management practices using the approach of personnel management in the first stage of the employee lifecycle to reduce insider threats. This was achieved by the recommendation of administrative methods such as policies and thorough background checks during the hiring of employees. These recommendations which allow the early detection of insider threats may not eliminate the insider threat in organisations. This is due to behavioural changes in humans. The application of more approaches in various phases of human resource management will help organisations combat the insider threat more effectively. The approaches suited for other phases of recruitment is beyond the scope of this paper, but an insider threat programme must cover all the stages of an employees lifecycle in the organisation. Therefore it is recommended that future studies cover other areas of this lifecycle.

For successful implementation of a robust human resource information security plan, there must be total adoption and change of mindset towards security by the management and employees. This means that more effort will be needed to change the mindset of organisations to accept cybersecurity as a role and responsibility for all stakeholders.

\section{REFERENCES}

[1] B. P. Zajac , People. The "other" half of computer security: Computers and security 1990. pp 301-303,

2] European Union Agency for Network and Information Security (ENISA). ENISA threat landscape report. 15 top cyber-threats and trends, heraklion. 2018. available online: https://www.enisa.europa.eu/publications/enisa-threat-landscapereport-2018 (accessed on 6 november 2021).

[3] M.T Bishop, The insider problem revisited: In Proceedings of the 2005 workshop on New security paradigms, 2005, pp. 75-76

[4] L. Ponemon, Cost of Data Breach Study: Global Analysis. Poneomon Institute Sponsored by Symantec. 2020, pp 1-31.

[5] D. Silva, B. Pappenheim, A.J da Silva, and J.E Davidsen. Information Security Governance, Technology, Processes and People: Compliance and Organisational Readiness: In Blockchain and Clinical TrialSpringer, Cham, 2019, pp. 89-113.

[6] P.A, Collier, Dixon, R. and Marston, C, Computer Fraud,Chartered Institute of Management Accountants,London, 1990.

[7] C. Carl. Human factors in information security: The insider threatWho can you trust these days?: Information security technical report 14.4 2009,pp. 186-196.

[8] E Grubdy P. Collier, and B Spaul, B. Computer Fraud: A People Problem?: Journal of Financial Crime, Vol. 1 No. 11993 , pp. 31-44.

[9] V. Raskin,, J.M Taylor and C.F Hempelmann , September. Ontological semantic technology for detecting insider threat and social engineering. In Proceedings of the 2010 :New Security Paradigms Workshop 2010, pp. 115-128.

[10] M. Warkentin \& R. Willison, Behavioral and policy issues in information systems security: the insider threa: European Journal of Information Systems, 18(2), 2009, pp. 101-105.

[11] V.P. Măzăreanu, About the human factor in risk management-primary source of uncertainty:Journal of Information Systems \& Operations Management, 2012 ,p. 6

[12] W.Arctic, The state of mid-market cybersecurity: Findings and implications. https://2p167arhj4lo70dn1q26fm1cwpengine.netdnassl.com/wp-content/uploads/- AW Brief Midmarket Cyberse. 2017

[13] L. Meshkat, R.L Miller, C. Hillsgrove, and J. King, Behavior modeling for cybersecurity: In proceedings of the 2020 annual reliability and maintainability symposium (RAMS), x IEEE 2020 ,pp $1-7$

[14] Symantec 2019 internet security threat report. https://docs.broadcom.com/doc/istr-24-2019- en (Accessed 19 Aug 2020).

[15] Conrad, H Stephen, F.A Duran, N Gregory . Conrad, David P. Duggan, and B.H Edward. Modeling the employee life cycle to address insider threat. No. SAND2009-5550C. Sandia National Lab.(SNL-NM), Albuquerque, NM (United States), 2009.

[16] Silowash, George \& Cappelli, Dawn \& Moore, Andrew \& Trzeciak, Randall \& Shimeall, Timothy \& Flynn, Lori. Common sense guide to prevention and detection of insider threats 4 th edition. carnegie mellon university cylab. 2012

[17] D. Andersen , M.C Dawn, J Jose, Gonzalez, Mohammad Mojtahedzadeh,P Andrew. Moore, and Eliot Rich. Preliminary 
system dynamics maps of the insider cyber-threat problem in proc. :22nd Int'l Conference of Sys Dynamics Society, Albany NY, The System Dynamics Society. 2004

[18] H Anderson, R T Bozek, T Longstaff, Wayne Meitzler, Michael Skroch, and Ken Van Wyk. Conference Proceedings :Research on mitigating the insider threat to information systems - \#2, CF-163DARPA, RAND National Defense Research Institute, Santa Monica CA: The RAND Corporation. 2000

[19] R Band, R Stephen , M. D Cappelli, L.F Fischer, A.P. Moore, E.D Shaw, and Randall F. Trzeciak. Comparing Insider IT Sabotage and Espionage: A Model-Based Analysis, Technical Report CMU/SEI2006-TR-026, ESC-TR-2006-091, Software Engineering Institute, Pittsburgh PA: Carnegie Mellon University. . 2006

[20] R Greitzer, F Frank \& Kangas, Lars \& Noonan, Christine \& Dalton, Angela. Identifying at-risk employees: A behavioral model for predicting potential insider threats. 2010

[21] A. Richard , J.H Caralli. D.W Allen, L W White ,Y.N Mehravari ,P.D Curtis :CERT ${ }^{\circledR}$ Resilience Management Model, Version 1.2 Human Resource Management (HRM) February 2016.

[22] M. Theoharidoua, S. Kokolakisb, M. Karydaa, \& E. Kiountouzisa The insider threat to information systems and the effectiveness of ISO17799. Computers \& Security 2005 , pp.472-484.

[23] W Hunker, Jeffrey, and W Christian . Probst. Insiders and Insider Threats-An Overview of Definitions and Mitigation Techniques. J. Wirel: Mob. Networks Ubiquitous Comput. Dependable Appl. 2.1 2011: pp 4-27.

[24] C.P Pfleeger, Charles . "Reflections on the insider threat." Insider attack and cyber security. Springer, Boston, MA, 2008. Pp 5-16.
[25] G.P Emma , P Collier, B Spaul, Auditing Personnel: ", Managerial Auditing Journal, Vol. 9 Iss 6 1994. " pp. 10 - 16 Permanent link to this document:http://dx.doi.org/10.1108/02686909410061233

[26] G. Dhillon, and S Moores. "Computer crimes: theorizing about the enemy within." Computers \& Security 20.8 2001. pp 715-723.

[27] S. Steele, Sean, and C. Wargo. An introduction to insider threat management:Information Systems Security 16.1 2007. Pp. 23-33.

[28] D.M Cappelli, A.P Moore, R.F Trzeciak, T.J Shimeall,. Common Sense Guide to Prevention and Detection of Insider Threats, Version 3.1: Carnegie Mellon University/CyLab. 2009

[29] E. Kowalski, D Cappelli, and A Moore. Insider threat study. Illicit cyber activity in the information technology and telecommunications sector.: carnegie-mellon univ pittsburgh pa software engineering inst, 2008

[30] D. Tapomoy. Strategic approach to human resource management. : Atlantic Publishers \& Dist, 2006.

[31] U. Schönenberg, Prozessexzellenz im HR-Management. Professionelle Prozesse mit dem HR-Management Maturity Model: Springer, Heidelberg 2010. pp 3-642-13325-1

[32] M. Burke, Six Stages to Success with the Employee Lifecycle. https://inside.6q.io/sixstages-to-success-with-the-employee-lifecycle/. Accessed 09 Apr 2019

[33] C. Williamson, Personnel management and security: Humanitarian Exchange, 2010, pp.14-15. 